Virginia Commonwealth University VCU Scholars Compass

\title{
Role of Epigenetic Modification and Immunomodulation in a Murine Prostate Cancer Model
}

JayE. Sulek

Virginia Commonwealth University, jay.sulek@gmail.com

Samuel P. Robinson

Virginia Commonwealth University

Albert A. Petrossian

Virginia Commonwealth University

See next page for additional authors

Follow this and additional works at: http://scholarscompass.vcu.edu/surgery pubs

Part of the Surgery Commons

(C) 2016 Wiley Periodicals, Inc.

\section{Downloaded from}

http://scholarscompass.vcu.edu/surgery_pubs/32

This Article is brought to you for free and open access by the Dept. of Surgery at VCU Scholars Compass. It has been accepted for inclusion in Surgery Publications by an authorized administrator of VCU Scholars Compass. For more information, please contact libcompass@vcu.edu. 
Authors

Jay E. Sulek, Samuel P. Robinson, Albert A. Petrossian, Shaoqing Zhou, Ekaterine Goliadze, Masoud H. Manjili, Amir Toor, and Georgi Guruli 


\title{
Role of Epigenetic Modification and Immunomodulation in a Murine Prostate Cancer Model
}

\author{
Jay E. Sulek, ${ }^{1 *}$ Samuel P. Robinson, ${ }^{1}$ Albert A. Petrossian, ${ }^{1}$ Shaoqing Zhou, ${ }^{1}$ \\ Ekaterine Goliadze, ${ }^{1,2}$ Masoud H. Manjili, ${ }^{2,3}$ Amir Toor, ${ }^{2}$ and Georgi Guruli ${ }^{1,2}$ \\ 'Division of Urology, Department of Surgery, Virginia Commonwealth University Medical Center, \\ Richmond, Virginia \\ ${ }^{2}$ Massey Cancer Center, Virginia Commonwealth University Medical Center, Richmond, Virginia \\ ${ }^{3}$ Department of Microbiology and Immunology, Virginia Commonwealth University School of Medicine, \\ Richmond, Virginia
}

\begin{abstract}
INTRODUCTION. Decreased expression of highly immunogenic cancer-testis antigens (CTA) might help tumor to achieve low immunogenicity, escape immune surveillance and grow unimpeded. Our aim was to evaluate CTA expression in tumor and normal tissues and to investigate possible means of improving the immune response in a murine prostate cancer $(\mathrm{CaP})$ model by using the combination of epigenetic modifier 5-azacitidine (5-AzaC) and immunomodulator lenalidomide. No study to date has examined the effect of this combination on the prostate cancer or its impact on antigen-presenting cells (APC).

MATERIALS AND METHODS. Gene microarrays were performed to compare expression of several CTA in murine prostate cancer (RM-1 cells) and normal prostate. RM-1 cells were treated with 5-AzaC and real-time PCR was performed to investigate the expression of several CTA. Western blotting was used to determine whether expression of CTA-specific mRNA induced by 5-AzaC resulted in increase in the corresponding protein. Effect of the epigenetic agents and immunomodulators was assessed on dendritic cells (DC) using flow cytometry, ELISA and T-cell proliferation assay.

RESULTS. Gene arrays demonstrated decreased expression of 35 CTA in CaP tissue compared to normal prostate. 5-AzaC treatment of RM-1 prostate cancer cells upregulated the expression of all 13 CTA tested in a dose-dependent fashion. DC were treated with 5-AzaC and lenalidomide and the expression of surface markers MHC Class I, MHC Class II, CD80, CD86, CD 205, and CD40 was increased. Combination of 5-AzaC and lenalidomide enhances the ability of DC to stimulate T-cell proliferation in mixed leukocyte reaction. Secretion of IL-12 and IL-15 by DC increased significantly with addition of 5-AzaC or 5-AzaC and lenalidomide.

CONCLUSIONS. Decreased expression of CTA by prostate cancer may be a means of escaping immune monitoring. Combination of epigenetic modifications and immunomodulation by 5 -AzaC and lenalidomide increased tumor immunogenicity and enhanced DC function and may be used in the treatment of advanced prostate cancer. Prostate 77: 361-373, 2017. (C) 2016 Wiley Periodicals, Inc.
\end{abstract}

KEY WORDS: 5-azacitidine; epigenetic modulation; prostate cancer; dendritic cells; lenalidomide

\section{INTRODUCTION}

The mainstay therapy for advanced prostate cancer is androgen deprivation therapy. However, following an initial period of positive response, prostate cancer over time becomes resistant to hormone therapy. Few options are available at that time and no treatment provides
Conflicts of interest: Nothing to disclose.

${ }^{*}$ Correspondence to: Jay Sulek, MD, Department of Surgery, Division of Urology, Virginia Commonwealth University School of Medicine, PO Box 980118, Richmond, VA 23298.

E-mail: jay.sulek@gmail.com

Received 23 May 2016; Accepted 21 October 2016

DOI 10.1002 /pros. 23275

Published online 8 November 2016 in Wiley Online Library (wileyonlinelibrary.com). 
long-term survival or cure. There is therefore an urgent need to develop alternative effective treatment modalities for advanced prostate cancer. In this article, we explored the value of epigenetic modification and immunomodulation in the prostate cancer environment.

One type of epigenetic aberration is DNA methylation which can occur as either hypo- or hypermethylation. Both forms can lead to chromosomal instability and transcriptional gene silencing and both have been implicated in a variety of human malignancies including prostate cancer [1]. Unlike genetic alterations such as mutations, epigenetic changes such as DNA methylation are potentially reversible. This property makes epigenetic modulation an attractive target for cancer therapy.

Although the list of epigenetically regulated genes continues to grow, only a few genes have, so far, given promising results as potential tumor biomarkers for early diagnosis and risk assessment of prostate cancer. Thus, large-scale screening of aberrant epigenetic events such as DNA hypermethylation is needed to identify prostate cancer-specific epigenetic fingerprints. More studies into the mechanism and consequence of demethylation are required before the cancer epigenome can be safely manipulated with therapeutics as a treatment modality.

5-Azacytidine and 5-aza-2'-deoxycytidine, nucleoside analog inhibitors of DNA methyltransferases (DNMT), have been widely used to reverse abnormal DNA hypermethylation and restore silenced gene expression. This induces changes which may be associated with development of a favorable phenotype in prostate cancer and could potentially be exploited in cancer immunotherapy.

One of the goals of cancer immunotherapy has been to find tumor-associated antigens (TAA) suitable as specific targets for immunotherapy. The ideal TAA is only expressed on tumor cells, is indispensable to tumor cell function, is expressed on most or all tumor cells, and induces a strong host immune response. Cancer testis antigens (CTA) are a group of in many cases highly immunogenic TAA expressed in embryonic stem cells and testicular germ cells which have attracted interest as potential targets of immunotherapy [2]. Despite the fact that most human malignancies simultaneously express multiple CTA, immune response to those antigens seems limited. In part, this is due to levels of expression that may be below the threshold for immune recognition in vivo. Epigenetic events, particularly DNA methylation, appear to be the primary mechanism regulating CTA expression in both normal and transformed cells, as well as in cancer stem cells [3-6].

Better antigen expression is not the only requirement of the immune response. Immune response must be tailored to that antigen. In this regard, we are exploring the impact of the immunomodulator lenalidomide-which has been shown to augment both innate and adaptive immune response and to improve antitumor effect [7-9]—in combination with DNA methylation inhibitors.

\section{MATERIALS AND METHODS}

\section{Mice}

Male C57BL/6 mice 6-8 weeks old and male BALB/c mice 6-8 weeks old were obtained from Taconic Farms (Germantown, NY). Animals were maintained at the Central Animal Facility at the Virginia Commonwealth University according to standard guidelines. All protocols used in this study were approved by the VCU Institutional Animal Care and Use Committee (IACUC).

\section{Dendritic Cells}

DC were generated from mice bone marrow cell precursors. Bone marrow cells were collected from tibias and femurs of Male C57BL/ 6 animals and resuspended in complete media, consisting of RPMI 1640 medium supplemented with $10 \%$ Heat Inactivated Fetal Bovine Serum (Gemini Bio-Products, West Sacramento, CA), $1 \mathrm{mM}$ sodium pyruvate (Quality Biological, Inc., Gaithersburg, MD), $10 \mathrm{mM}$ MEM Non-Essential Amino Acids (Gibco), $100 \mathrm{U} / \mathrm{ml}$ penicillin (Gibco), $100 \mathrm{mg} / \mathrm{ml}$ streptomycin (Gibco). The cell suspension was disrupted by pipetting, filtered through a 70- $\mu \mathrm{m}$ filter, and then cells were depleted of RBC with ACK lysing buffer (Quality Biological, Inc., Gaithersburg, MD) for 2-3 min. Cells were incubated overnight in six-well plates at a concentration of $10^{6}$ cells $/ \mathrm{ml}$ in $4 \mathrm{ml}$ of complete media per well. The next day, non-adherent cells were collected by gentle pipetting and were then resuspended at a concentration of 250,000 cells $/ \mathrm{ml}$ in complete medium. Both recombinant murine GM-CSF (Invitrogen, Carlsbad, CA) and recombinant murine IL-4 (Gemini Bio-Products, West Sacramento, CA) were added to a final concentration of $50 \mathrm{ng} / \mathrm{ml}$. Cells were cultured in six-well plates $\left(4 \mathrm{ml} /\right.$ well) for 7 days at $37^{\circ} \mathrm{C}$ in a humidified atmosphere containing $5 \% \mathrm{CO}_{2}$ with an additional supplementation of GM-CSF and IL-4 on Day 4. For differentiation into mature DC, cells were additionally stimulated on Day 5 with $50 \mathrm{ng} / \mathrm{ml}$ TNF $\alpha$ (Invitrogen, Carlsbad, CA) for $48 \mathrm{hr}$. On Day 7, immature and mature dendritic cells were harvested for further studies.

\section{Prostate Cancer Cell Line}

RM-1 cell line is an androgen-independent murine prostate cancer cell line. It was a gift from Dr. Timothy C. Thompson (Baylor College of Medicine, Houston, 
TX). This model was generated by transduction of cells with the ras and myc oncogenes, yielding a poorly differentiated adenocarcinoma. Tumor cells were maintained in complete media at $37^{\circ} \mathrm{C}$ in $5 \%$ CO2. For in vivo studies, RM-1 cells (50,000 cells/ $100 \mu \mathrm{l})$ were inoculated subcutaneously (SC) into the right shaved flank of C57BL/6 mice, and tumor establishment was determined by palpation. Tumor growth was assessed every other day by microcalipers. Mice were euthanized when tumors reached a volume of $3,000 \mathrm{~mm}^{3}$ or if the mice became moribund or cachectic.

\section{Study Compounds}

Lenalidomide and 5-AzaC were free gifts from Celgene Corporation (Summit, NJ). Lenalidomide was dissolved in 100\% dimethylsulfoxide (DMSO) (Sigma-Aldrich, St. Louis, MO) before further dilution in cell culture media. Final DMSO concentrations were kept at a constant $0.1 \%$ for all samples, including controls, unless otherwise stated. Lenalidomide was used at a final concentrations of 0.5, 1.0, 2.0 and $10 \mu \mathrm{M}$. 5-AzaC was dissolved as $1.0 \mathrm{mmol} / \mathrm{L}$ stock solution in PBS and stored at $-20^{\circ} \mathrm{C}$. 5 -AzaC was added to tissue culture medium daily at final concentrations of 1.0 and $0.5 \mu \mathrm{M}$. Both drugs were maintained as stock solutions for in vitro experiments at $-20^{\circ} \mathrm{C}$ for no longer than 1 month.

\section{Cell Proliferation Assay}

Cell proliferation was measured using a colorimetric assay with WST-1 reagent, which quantifies mitochondrial metabolic activity of viable cells per manufacturer's instructions (Roche, Indianapolis, IN). Cells were cultured in 96-well microplates in a concentration of $5 \times 10^{4}$ cells $/ \mathrm{ml}$ (in RPMI with $10 \%$ FBS) and cultivated for $48 \mathrm{hr}$ in a humidified atmosphere $\left(37.0^{\circ} \mathrm{C} ; 5 \% \mathrm{CO} 2\right)$. After $44 \mathrm{hr}, 10 \mu \mathrm{l}$ of WST-1 was added and cells were incubated for an additional $4 \mathrm{hr}$. During this incubation period, viable cells convert WST- 1 to a water soluble formazan dye. Cell viability was measured at $450 \mathrm{~nm}$ in a microplate reader (Bio Rad) (Reference wavelength: $655 \mathrm{~nm}$ ). Combined results of three experiments are presented.

\section{Annexin V Assay}

DC were collected and double stained with FITC-conjugated annexin $\mathrm{V}$ and 7-AAD, according to the manufacturer's instructions (Biolegend, San Diego, CA). Briefly, DC were collected after $48 \mathrm{hr}$ of culture under different conditions, washed twice with cold
Biolegend's Cell Staining Buffer and then resuspended in Annexin $\mathrm{V}$ Binding Buffer at a concentration of $10^{5}$ cells $/ \mathrm{ml}$. Cells were incubated with Annexin V-FITC and 7-AAD for $15 \mathrm{~min}$ at room temperature. After washing steps, all samples were analyzed within $30 \mathrm{~min}$. Data were acquired using a BD FACSCANTO II benchtop analyzer (Becton Dickinson, San Jose, CA) and analysis was performed using BD FACSDiva software (BD) and FCS Express (De novo software, Los Angeles, CA).

\section{Flow Cytometry}

DC phenotype was evaluated using flow cytometry analysis. Dendritic cells were collected and suspended in FACS buffer (1\% FCS and $15 \mathrm{mM} \mathrm{NaN}_{3}$ in PBS). Cells were preincubated for $15 \mathrm{~min}$ with immunoglobulin constant Fragment $\left(\mathrm{F}_{\mathrm{C}}\right)$-receptor blocking antibody (purified anti-CD16/CD32, Clone 93) to reduce nonspecific binding. Then dendritic cells were stained for $20 \mathrm{~min}$ at $4^{\circ} \mathrm{C}$ with optimal dilution of relevant antibodies directly conjugated with Alexa Fluor or PE. The following mAbs (clone name given in parentheses) were used: Alexa Fluor-labeled antimouse CD11c (clone N418, Invitrogen) and PE-labeled anti-mouse CD40 (clone 3/23, Invitrogen), F4/80 (clone BM8, Invitrogen), CD86 (clone P0.3, Invitrogen), MHC class II (I-A) (clone NIMR-4, eBioscience, San Diego, CA), CD205 (clone NLDC-145, Miltenyi Biotec, San Diego, CA), I-Ad/I-Ed (clone 2G9, Becton Dickinson, San Jose, CA). DC were identified based on forward scatter, CD11c expression and low auto fluorescence. We collected 10,000 events per sample. Data were acquired using a BD FACSCANTO II benchtop analyzer (Becton Dickinson, San Jose, CA) and analysis was performed using BD FACSDiva software (BD) and FCS Express (De novo software, Los Angeles, CA).

\section{Cytokine Detection Assay}

DC culture supernatants were harvested and cellular debris was removed by centrifugation. Concentration of soluble cytokines IL-12-p70 and IL-15 were measured by eBioscience's (San Diego, CA) quantitative enzyme-linked immunosorbent assays. Briefly, 96-well Corning Costar ELISA plates were coated with the appropriate capture antibodies overnight. After blocking the plates and a further $2 \mathrm{hr}$ incubation with supernatants or standard, the plates were developed using biotin-conjugated anticytokine antibodies. Samples and standards were run as triplicates in every assay, and were read at $450 \mathrm{~nm}$ wavelength on a benchmark microplate reader (Bio-rad, Hercules, CA). Cytokine concentrations were normalized based on 
cell counts and determined by computer softwaregenerated interpolation from the standard curve. They are presented as $\mathrm{pmol} / \mathrm{ml}$.

\section{RNA Isolation}

At the time of euthanasia, tissues were harvested in an RNase-free manner. Tumor or normal prostate were either snap frozen in liquid nitrogen and stored at $-80^{\circ} \mathrm{C}$ until RNA isolation or used immediately for RNA isolation. RNA from snap frozen tissue or fresh tissue was routinely isolated by TRIzol (Invitrogen, Carlsbad, CA). For that, tissue was placed in cold TRIzol $\left(4^{\circ} \mathrm{C}\right)$ and immediately homogenized using a Bio-Gen PRO200 Homogenizer (Pro scientific Inc., Oxford, CT) The protocol for TRIzol isolation was then completed following the manufacturer's instructions. Isolated RNA was purified with an RNeasy Mini Kit (Qiagen, Valencia, CA). RNA yields were determined spectrophotometrically at $260 \mathrm{~nm}$.

\section{Gene Microarray}

Affymetrix GeneChip Mouse Genome 430 V2.0 was used for RM-1 cells and normal murine prostate tissue cells with 45000 probes. Following the RNA isolation procedure, synthesis of double-stranded cDNA was performed using the GeneChip 3' IVT Plus Reagent kit from Affymetrix (Santa Clara, CA). For first-strand cDNA synthesis, a T7-Oligo(dT) primer containing a T7 promoter site was used. After second-strand synthesis, the double-stranded cDNA was used as a template for in vitro transcription. In this step, labeled complementary RNA (cRNA) was synthesized and amplified by in vitro transcription (IVT) of the second-stranded cDNA template using T7 RNA polymerase. The cRNA was then purified to remove enzymes, salts, inorganic phosphates and unincorporated nucleotides. Following quantitation at $\mathrm{A}_{260}$, the labeled cRNA was fragmented to 35-200 base fragments by divalent cations and elevated temperature. Fifteen $\mu \mathrm{g}$ of fragmented cRNA were hybridized for sixteen hours at $45^{\circ} \mathrm{C}$ in the appropriate GeneChip Probe Array using the GeneChip Hybridization Oven. Spiked hybridization controls include labeled transcripts from Escherichia coli bioB, bioC and bioD, cre from bacteriophage P1, and synthetic Oligo B2. Following hybridization, the arrays were washed and stained in an Affymetrix GeneChip Fluidics Station. Staining was done in a three-step procedure starting with a streptavidin-phycoerythrin staining solution, followed by incubation with biotinylated antistreptavidin and finally a second staining with streptavidin-phycoerythrin. Stained arrays were scanned using Affymetrix GeneChip Scan- ner. Analysis of data was performed using the Affymetrix Expression Console Software. In a basic initial analysis, genes that had fold change values of $>1.0$ and a $P$-value $<0.05$ were considered significantly differentially expressed for analysis.

\section{Quantitative Real Time Polymerase Chain Reaction (qRT-PCR)}

After RNA isolation, cDNA was synthesized using the ThermoScript RT-PCR System (Invitrogen) from $1 \mu \mathrm{g}$ of total RNA using Random Primer. In each experiment, at least three independent reactions were performed to obtain the mean. QRT-PCR was performed in triplicate including a non-template control using the Mx3000P system (Agilent Technologies, Inc., Santa Clara, CA). Oligos (Invitrogen) were designed using Primer3 software (White head Institute of Biomedical Research MIT. Boston, MA), and are presented in Table I. GAPDH and P1A Primers were obtained from Qiagen.

Real-time RT-PCR reactions were performed in $20 \mu \mathrm{l}$ volumes with $10 \mu \mathrm{l}$ of SensiFAST SYBR Lo-ROX Kit (Bioline, Taunton, MA) $2 \mu \mathrm{l}$ of cDNA template and $0.5 \mu l$ each of the forward and reverse primers of the gene of interest (GOI). The cDNA used for the PCR reactions was diluted 1:35 for each GOI. PCR conditions were as follows: an initial denaturation step $\left(10 \mathrm{~min}\right.$ at $\left.95^{\circ} \mathrm{C}\right), 40$ cycles consisting of three steps( $30 \mathrm{sec}$ at $95^{\circ} \mathrm{C}, 1 \mathrm{~min}$ at $55^{\circ} \mathrm{C}, 30 \mathrm{sec}$ at $72^{\circ} \mathrm{C}$ ), and 1 cycle consisting of three steps $\left(1 \mathrm{~min}\right.$ at $95^{\circ} \mathrm{C}, 30 \mathrm{sec}$ at $55^{\circ} \mathrm{C}$, and $30 \mathrm{sec}$ at $95^{\circ} \mathrm{C}$ ). The cycle threshold (CT) value was the PCR cycle number in which the fluorescence signal was significantly distinguishable from the baseline for the first time.

The housekeeping gene (GAPDH) was used as an endogenous control for target gene expression evaluation. Expression values of each gene were normalized to the expression of GAPDH of a given sample. Data were presented by the relative amount of mRNA with the formula $2^{-\Delta \Delta} \mathrm{CT}$, which stands for the difference between the CT of a gene of interest and the CT of the housekeeping gene (GAPDH).

\section{Western Blots}

For Western blot analyses, protein was harvested from cells plated to $70-80 \%$ confluence. Cells were homogenized in RIPA lysis buffer $(20 \mathrm{mM}$ tris, $50 \mathrm{mM}$ $\mathrm{NaCl}, 2 \mathrm{mM}$ EDTA, $2 \mathrm{mM}$ EGTA, $1 \%$ sodium deoxycholate, $1 \%$ Triton $\mathrm{X}-100$ (TX-100), and $0.1 \%$ SDS, $\mathrm{pH}$ 7.4), containing a protease inhibitor cocktail (1:100, Sigma) and phosphatase inhibitor cocktails 1 and 3 (both at 1:200, Sigma). Lysates were cleared by 
TABLE I. Primers for Polymerase Chain Reaction (PCR)

\begin{tabular}{|c|c|c|c|}
\hline Gene & Accession number & Primer sequence $\left(5^{\prime}\right.$ to $\left.3^{\prime}\right)$ & Product length \\
\hline Ccna1 & NM_007628 & $\begin{array}{l}\text { Forward - GAAGAACCTGAGAAGCAGGGC } \\
\text { Reverse - AGCTCTGCTGAGCATTTGACA }\end{array}$ & $131 \mathrm{bp}$ \\
\hline Adam2 & NM_009618 & $\begin{array}{l}\text { Forward - AGGTGCATTACTCTACGCCG } \\
\text { Reverse - TCAGCCCCGATATGCTCAAA }\end{array}$ & $147 \mathrm{bp}$ \\
\hline Cep55 & NM_028760 & $\begin{array}{l}\text { Forward - GAAAAACTCGACCGCCAGAA } \\
\text { Reverse - GCTGCAAGGATTCCAACTGT }\end{array}$ & $100 \mathrm{bp}$ \\
\hline Tex15 & NM_031374 & $\begin{array}{l}\text { Forward - GCTTCTCATCAACCAGTCCCA } \\
\text { Reverse - AAGGCCTTCGTAGAAACGGAT }\end{array}$ & $118 \mathrm{bp}$ \\
\hline Spa17 & NM_011449 & $\begin{array}{l}\text { Forward - CGCACCAGCTTGAAGAGAAAG } \\
\text { Reverse - ATTCGGTAGTGGGTGTTGGA }\end{array}$ & $90 \mathrm{bp}$ \\
\hline Tdrd1 & NM_001002238 & $\begin{array}{l}\text { Forward - GGTCTTCCCACAGCACCATCT } \\
\text { Reverse - TAACTCCCGGGGGACAGTCAA }\end{array}$ & $126 \mathrm{bp}$ \\
\hline Ndn & NM_010882 & $\begin{array}{l}\text { Forward - TCTGCGGGAGGCTAATCTTG } \\
\text { Reverse - TCAACCCCACCCTTACACAG }\end{array}$ & $121 \mathrm{bp}$ \\
\hline Akap4 & NM_009651 & $\begin{array}{l}\text { Forward - GAGTCATCGCAGCATCCAAA } \\
\text { Reverse - AAGATCTACCTTGCACACGC }\end{array}$ & $135 \mathrm{bp}$ \\
\hline Acrbp & NM_016845 & $\begin{array}{l}\text { Forward - TACCTGCACCATGACTCCCAC } \\
\text { Reverse - GTCGCCTTCCGAGATTGTCAC }\end{array}$ & $98 \mathrm{bp}$ \\
\hline Odf4 & NM_145746 & $\begin{array}{l}\text { Forward - GGCTCCTGTACATCTGCGTA } \\
\text { Reverse - GAGGACAAAACCCAGCCCTA }\end{array}$ & $140 \mathrm{bp}$ \\
\hline Dkkl1 & NM_015789 & $\begin{array}{l}\text { Forward - CGACTCTCAGCAGAACACCT } \\
\text { Reverse - TTGTCCAGGTCTCGTAGCAG }\end{array}$ & $102 \mathrm{bp}$ \\
\hline Boris & NM_001081387 & $\begin{array}{l}\text { Forward - CAAGTGCTCCCTGTGCAAGTAC } \\
\text { Reverse - CGTGTGTGAGCGGATGTGA }\end{array}$ & $70 \mathrm{bp}$ \\
\hline
\end{tabular}

centrifugation (20 min at 14,000g), diluted with $2 \times$ SDS sample buffer and boiled.

Immunoblotting was conducted by standard protocols with an equal amount of total protein $(10 \mu \mathrm{g})$ per lane. The protein extracts were loaded, size-fractionated by SDS-polyacrylamide gel electrophoeresis and transferred to PVDF membranes (Bio-Rad Laboratories). After blocking, the membranes were incubated with the specific rabbit polyclonal antibodies in dilution buffer at $4^{\circ} \mathrm{C}$ overnight. The blotted membranes were incubated with HRP-conjugated goat anti-rabbit IgG $(1: 1,000)$ at room temperature for $2 \mathrm{hr}$. Subsequently, the targeting protein expression level was detected and visualized using the Enhanced Chemiluminescence (ECL) detection system. Primary antibodies Cyclin A1 (H-230) and CEP55 (H-300) (Santa Cruz Biotechnology) were used at 1:500 dilution. GAPDH was used as the internal control.

\section{T Cell Proliferation Assay}

Functional activity of DC was determined in the primary allogeneic mixed leukocyte reaction (MLR) assay using mouse $\mathrm{T}$ lymphocytes as responder cells. DC used as stimulators and were generated from bone marrow progenitors of C57BL/6 mice.
Allogeneic $\mathrm{T}$ cells, obtained from the spleens of $\mathrm{BALB} / \mathrm{c}$ mice, served as responders. $\mathrm{T}$ cells were generated using mouse $\mathrm{T}$ cell enrichment columns (R\&D Systems, Minneapolis, MN). Dendritic cells were stimulated with TNF $\alpha$ and treated with different concentrations of 5-AzaC. DC were collected after $48 \mathrm{hr}$ of culture under different conditions, washed twice to remove any cytokine and cocultured with freshly purified $3 \times 10^{5}$ Allogenenic CD3 + T cells. The MLR assays were carried out in round bottomed 96-well plates where DC were added in triplicates in graded doses $\left(10^{3}-10^{5}\right.$ cells $/$ well $)$ to $\mathrm{T}$ cells $\left(3 \times 10^{5}\right.$ cells /well) in a total volume of $200 \mu 1$. Proliferation of $\mathrm{T}$ cells was measured by uptake of $3 \mathrm{H}$-thymidine ( 1 $\mathrm{Ci} /$ well, $5 \mathrm{Ci} / \mathrm{mmol}$;) pulsed for 16-18 hr after 3 days in culture. Incorporation of ${ }^{3} \mathrm{H}$-thymidine was determined on a LS 6500 Scintillation System (Beckman Coulter, Fullerton, CA).

\section{Statistical Analysis}

The Student $t$ test was used for comparison of two groups (SigmaPlot Software; SPSS, Chicago, IL). If data distribution was not normal, the Mann-Whitney rank sum test was used instead. A z-test was performed to evaluate the significance of differences between the experimental groups in the flow cytometry assays 
when discrete data were presented. For all analysis, the level of significance was set at a probability of 0.05 to be considered significant. Data are presented as the mean \pm standard error of the mean (SEM).

\section{RESULTS}

\section{Influence of 5-AzaC and Lenalidomide on RM-I Cells Proliferation}

Cell proliferation assay. RM-1 cells in suspension were exposed to 4 different concentrations of lenalidomide $(0.5,1.0,2.0$, and $10 \mu \mathrm{M})$. A DMSO control and one group with no treatment were also included. The cell proliferation assay was then performed. The differences in cell proliferation between groups did not reach statistical significance. For 5-AzaC, 2 different concentrations $(0.5$ and $1.0 \mu \mathrm{M})$ were used. One group with no treatment was also included as a control. Cell proliferation decreased in a dose-dependent fashion with increasing concentrations of 5-AzaC. The difference between the control and RM-1 cells treated with both concentrations of 5-AzaC were statistically significant $(P=0.016$ for the group treated with the concentration of $0.5 \mu \mathrm{M}$ and $P=0.004$ for the group treated with the concentration of $1.0 \mu \mathrm{M}$ of $5-\mathrm{AzaC})$. There was no statistically significant difference between the 5 -AzaC treated groups. Addition of lenalidomide $(0.5 \mu \mathrm{M})$ did not significantly affect cell proliferation.

\section{Dendritic Cell Apoptosis Induced by 5-Azacitidine and Lenalidomide}

We utilized Annexin V/7-ADD staining to establish noncytotoxic concentrations for 5-AzaC and lenalidomide. Cells were treated with various concentrations of 5-AzaC and lenalidomide alone and in combination. Results are presented in Figure 1. Apoptosis was increased with higher concentrations of 5-AzaC alone. Lenalidomide had a milder effect on DC death as concentration increased. Addition of lenalidomide to 5-AzaC seems to lower apoptotic rate at lower concentrations of 5-AzaC, but higher concentrations of 5-AzaC still seems to be quite toxic to DC. These experiments allowed the establishment of nontoxic concentrations of these compounds for ex vivo studies.

\section{Expression of Co-Stimulatory Molecules on Dendritic Cells}

Dendritic cells initiate T-cell activation by presenting MHC-bound antigen and co-stimulation markers to the naive T-cell. The maturation status

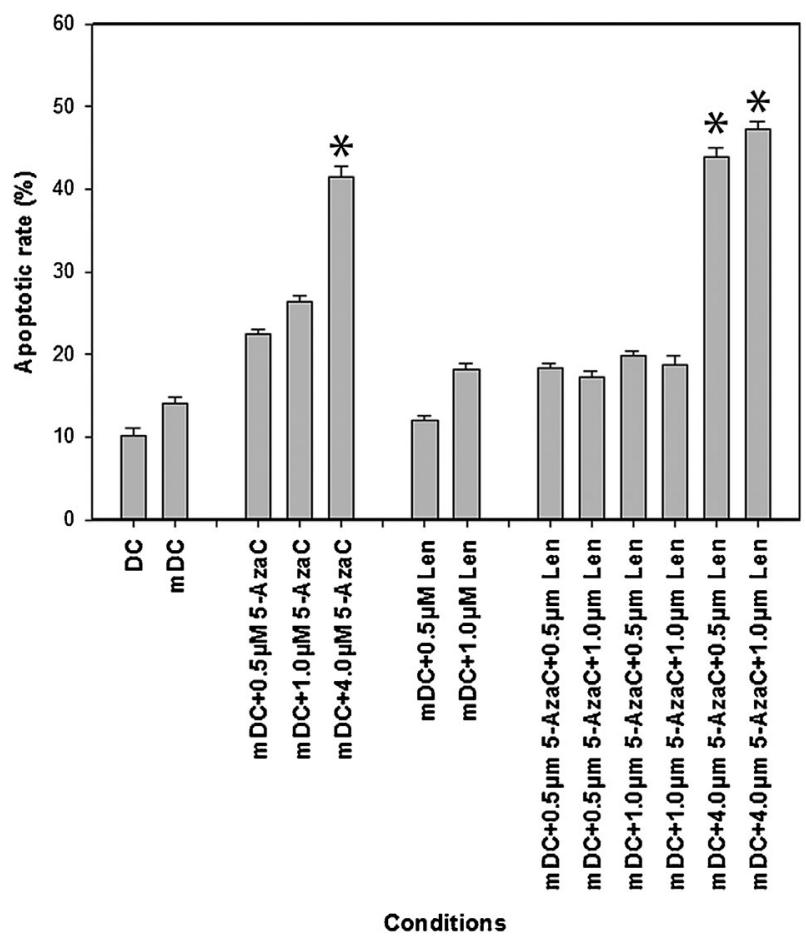

Fig. I. Rate of DC apoptosis by Annexin $\mathrm{V}$ assay after exposing $\mathrm{DC}$ to different combinations of 5 -azaC and lenalidomide. Mature $\mathrm{DC}(\mathrm{DC}+\mathrm{TNF} \alpha)$ were treated either with 5 -AzaC or Lenalidomide for $48 \mathrm{hr}$ and drug-induced apoptosis was assessed by Annexin $\mathrm{V}$ binding assay. Untreated mature DC served as a control. After $48 \mathrm{hr}$ of treatment, DC were collected, stained with Annexin $\mathrm{V}$ and propodium iodide $(\mathrm{PI})$ and flow cytometry was performed for annexin-positive (early and late apoptotic) cells. Data were acquired using BD FASCANTO II benchtop analyzer (Becton Dickinson, San Jose, CA). The percentage of apoptotic cells was analyzed by BD FACSDiva software (BD) and FCS Express (De novo software, Los Angeles, CA). High concentration of 5-AzaC proved to be significantly toxic to DC. DC, dendritic cells; mDC, mature DC, 5-AzaC, 5-azacitidine; Len, lenalidomide. *Depicts statistically significant difference in comparison to mature DC.

of DC is a key factor required for the induction of a specific immune response, and relies on the presentation of antigens by fully mature DC. Lenalidomide $(0.5 \mu \mathrm{M}), 5$-AzaC $(1.0 \mu \mathrm{M})$ and the combination of the two were added during the last $48 \mathrm{hr}$ of culture after which time DC were harvested, stained with antibodies for MHC class I, MHC class II, CD40, CD80, CD86, and CD205 and flow cytometry was performed. The experiment was repeated three times and the composite results are presented in Figure 2. As demonstrated, there was an increase in the expression of all DC markers when exposed to lenalidomide or 5-AzaC. The greatest increase in markers was seen with the combination of the two drugs, and that increase in expression was between 


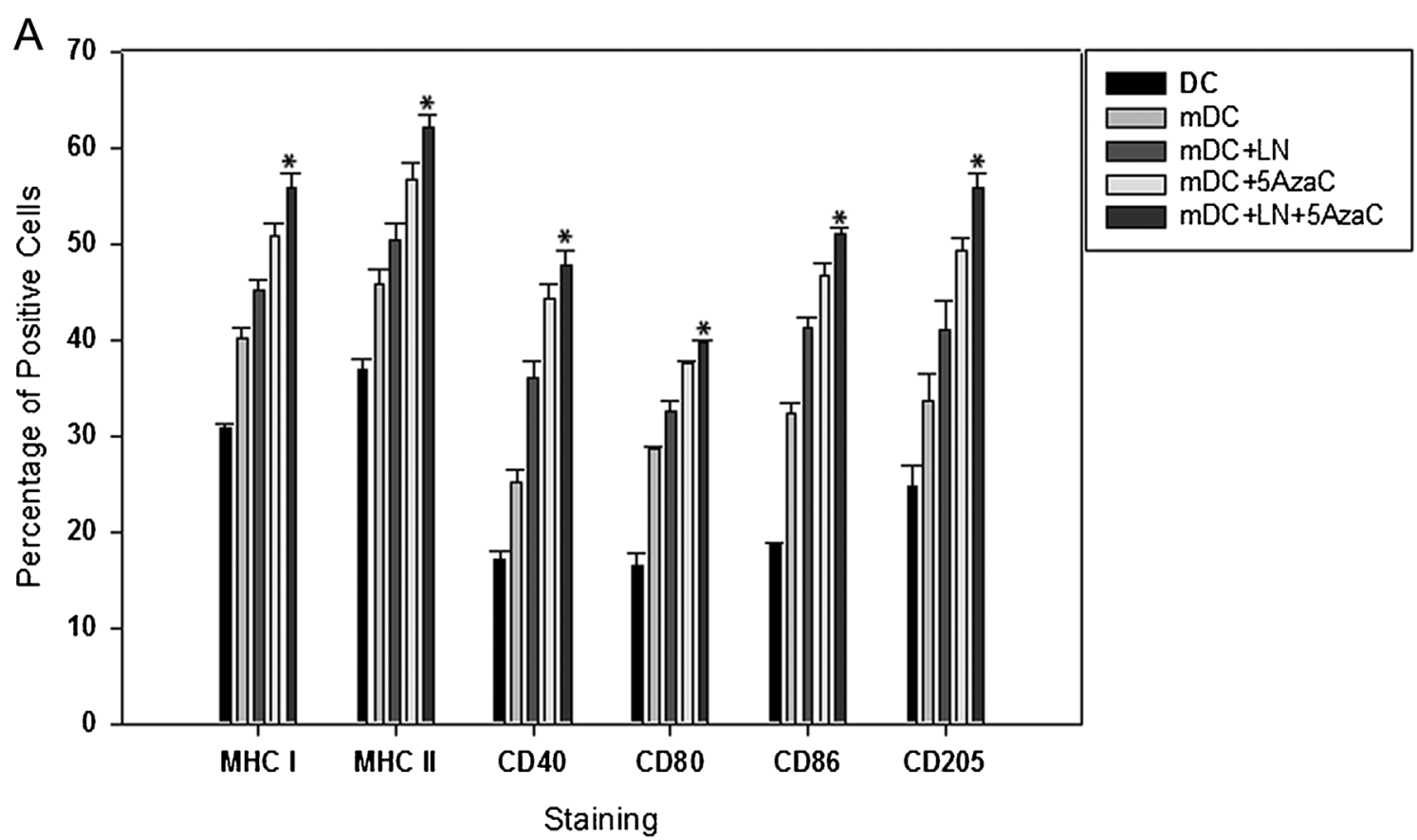

B
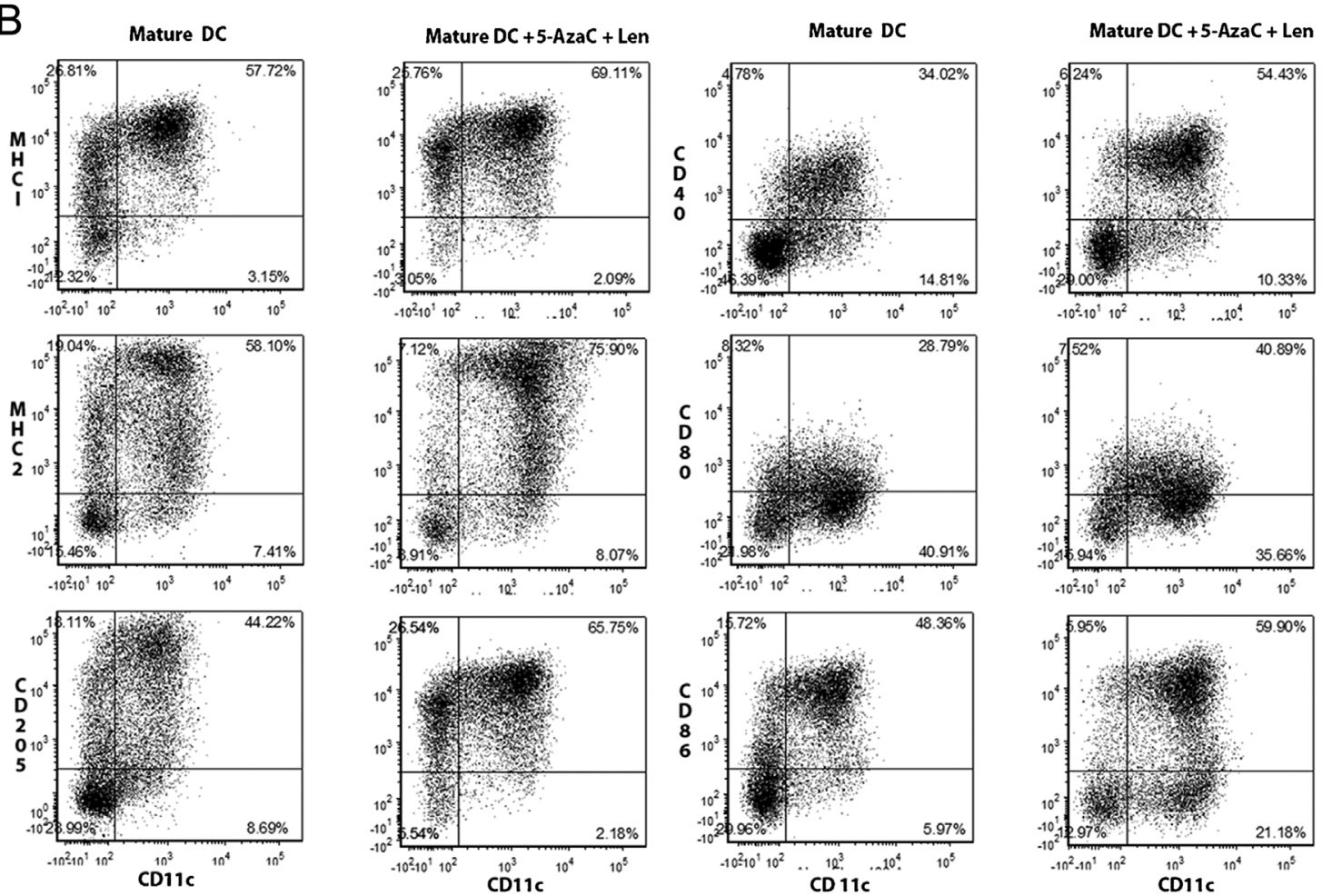

Fig. 2. DC were analyzed after 7 days of culture with GM-CSF and IL-4, with addition of TNF $\alpha$ for the last $48 \mathrm{hr}$ Lenalidomide $(0.5 \mu \mathrm{M})$ and $5-\mathrm{AzaC}(1.0 \mu \mathrm{M})$ were added alone or in combination to the DC culture during the last $48 \mathrm{hr}$, together with TNF $\alpha$. DC treated with DMSO $(0.1 \%$, solvent for lenalidomide) provided control. Treated cells were harvested and washed in FACS buffer and stained with appropriately diluted antibodies directly conjugated with Alexa Flour or PE. DC were evaluated phenotypically by flow cytometry to assess expression of surface molecules. Flow cytometry analysis revealed that the percentage of double-positive CD I I / MHC II, CD I Ic/CD86, CDIIc/CD80, CDIIc/MHC I, CDIIc/CD205, and CDIIc/CD40 cells was increased after their treatment with 5-AzaC and lenalidomide. DC, dendritic cells; mDC, mature DC; LN, lenalidomide; 5-AzaC, 5-azacitidine. A: Bar graph depicting the expression of co-stimulatory molecules on DC (combined results). ${ }^{*}$ Depicts statistically significant difference in comparison to mature DC. B: Comparison dot-plots for the expression of co-stimulatory molecules by mature dendritic cells treated with solvent (DMSO, $0.1 \%$ ) and with the combination of 5-azacitidine (5-AzaC) and lenalidomide ( $\mathrm{LN})$. The results of one of three representative experiments are shown. 
$11 \%$ and $22 \%$ for different markers. Results achieved statistical significance $(P<0.001)$.

\section{ELISA for IL-I 2 and IL-I5}

Dendritic cells were grown in culture, matured with TNF $\alpha$, and treated for the last $48 \mathrm{hr}$ with $1.0 \mu \mathrm{M}$ 5-AzaC and/or $0.5 \mu \mathrm{M}$ lenalidomide. Untreated DC provided the control (Fig. 3). The production of IL-12 and IL-15 was identified in all groups using ELISA. Administration of 5-AzaC resulted in statistically significant increase in the production of both IL-12 and IL-15 $(P<0.001$ for both). Administration of lenalidomide alone had no significant effect on the level of either cytokine. Combined use of 5-AzaC and lenalidomide resulted in significantly elevated production of both cytokines in comparison to mature DC $(P<0.001)$ and DC treated with lenalidomide only. Comparing the combined group to that treated with 5-AzaC alone, production of IL-15 was significantly increased $(P<0.001)$ in the combined group. IL-12 production was increased in the combined group but increase did not reach statistical significance $(P=0.08)$.

\section{T-Cell Proliferation Assay}

In this experiment, we evaluated the influence of 5-AzaC (concentration $1.0 \mu \mathrm{M}$ ) and or lenalidomide (concentration $0.5 \mu \mathrm{M}$ ) on the ability of DC to stimulate $\mathrm{T}$ cells. DC were generated from bone marrow progenitors of C57BL/6 mice. Allogeneic T cells, obtained

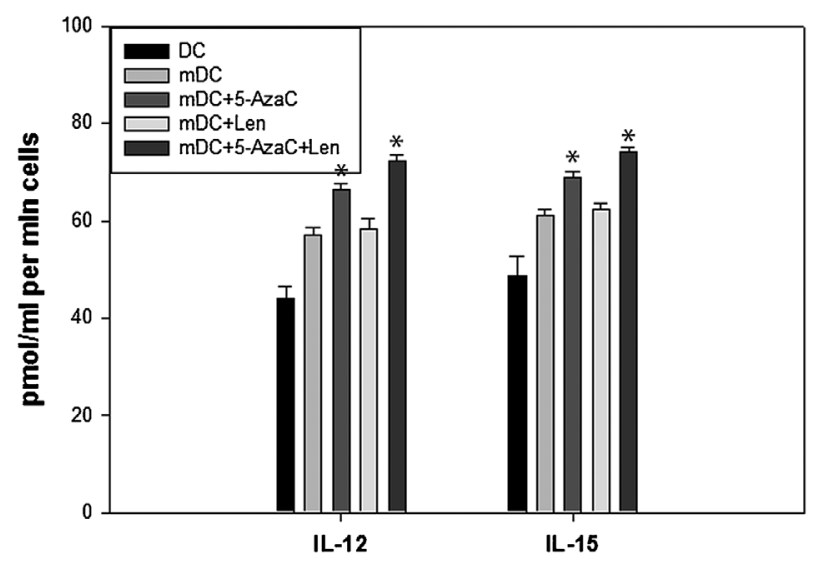

Fig. 3. The production of IL-I2 and IL-I5 by mature DC (treated with TNF $\alpha$ ) after exposure to 5-AzaC (I.0 $\mu \mathrm{M})$ only, lenalidomide $(0.5 \mu \mathrm{M})$ only, and co-treatment groups for $48 \mathrm{hr}$. Supernatant of DC were collected after the treatment and ELISA was performed to determine the concentration of cytokines. DC, dendritic cells; TNFa, tumor necrosis factor $\alpha$; 5-AzaC, 5-azacitidine; Len, Lenalidomide. ${ }^{*}$ Depicts statistically significant difference in comparison to mature DC. from the spleens of BALB/c mice, served as responders. DC were stimulated with TNF $\alpha$ and were exposed to 5-AzaC and/or lenalidomide for the last $48 \mathrm{hr}$ of culture. Plain DC and DC with TNF $\alpha$ alone served as controls. Both 5-AzaC and lenalidomide induced activation of DC. Difference in T cell stimulation for the 5-AcaC alone and lenalidomide alone groups was statistically significant for the DC concentrations 1:27 and 1:81 $(P<0.001)$ compared to controls. Exposure to both lenalidomide and 5-AzaC resulted in a statistically significant difference in $\mathrm{T}$ cell stimulation for $\mathrm{DC}$ concentrations of 1:27, 1:81, 1:243, and 1:729 compared to controls. T cell stimulation for this combined group was statistically increased compared to the lenalidomide alone group at all concentrations and was statistically increased compared to the $5-\mathrm{AzaC}$ alone group at concentrations of 1:27 and 1:81 $(P=0.024)$ (Fig. 4).

\section{Gene Arrays}

Expression of CTA in normal murine prostate tissue and RM-1 prostate cancer tumor cells was

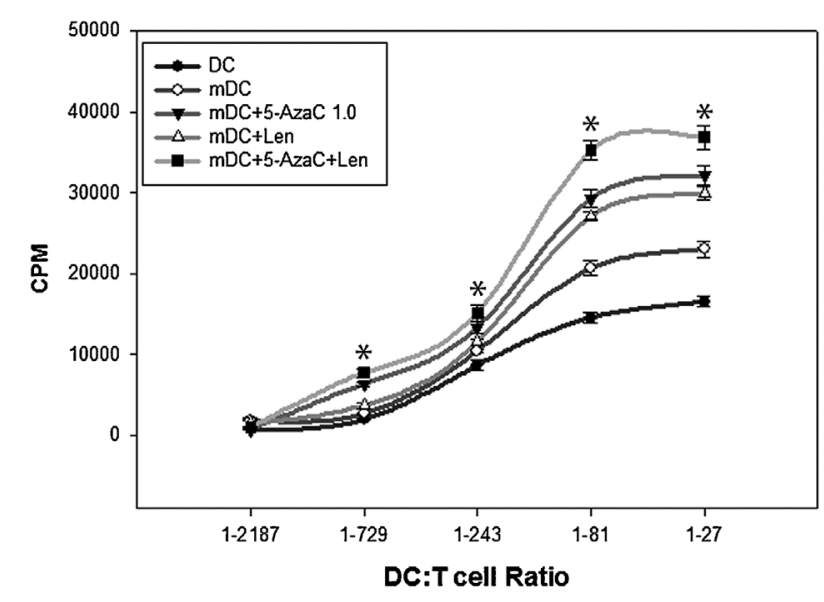

Fig. 4. 5-AzaC and Lenalidomide increase the ability of mature DC to stimulate T-cell proliferation in a dose-dependent manner in a standard MLR. Allogenic T cells obtained from the spleens, served as responders. DC used as stimulators were generated from bone marrow progenitors. DC were matured with TNF $\alpha$ for $48 \mathrm{hr}$. Mature DC were treated with 5-AzaC (I.0 $\mu \mathrm{M})$ only, Lenalidomide $(0.5 \mu \mathrm{M})$ only, or combined 5 -AzaC/Lenalidomide. DC were then washed, resuspended in complete medium, counted using trypan blue, and added to $T$ cells at different ratios in triplicates. The starting number of live (trypan blue negative) $\mathrm{DC}$ was the same in each group. DC were added in graded doses $\left(10^{3}-10^{5}\right.$ cells/well $)$ to $\mathrm{T}$ cells $\left(3 \times 10^{5}\right.$ cells/well $)$ and proliferation of $\mathrm{T}$ cells was measured by uptake of ${ }^{3} \mathrm{H}$-thymidine. Data represent the mean \pm S.E.M. of triplicate measurements from three independent experiments. Values represent the count per minute (cpm) in the presence or absence of study compounds. DC, dendritic cells; mDC, mature DC; 5-AzaC, 5-azacitidine, Len, Lenalidomide. *Depicts statistically significant difference between the $\mathrm{mDC}+5-\mathrm{AzaC}+$ Lenalidomide and mature DC groups. 
TABLE II. The Microarray Expression Profile of 35 CTA

\begin{tabular}{|c|c|c|}
\hline $\begin{array}{l}\text { Fold change (normal } \\
\text { prostate/RM-1 cells) }\end{array}$ & Common name & Probe description on MG 4302.0 chip \\
\hline 253.375 & DKKL1 & Dickkopf-like 1 \\
\hline 102.026 & TULP2 & Tubby-like protein 2 \\
\hline 45.535 & Tex15 & Testis expressed gene 15 \\
\hline 32.591 & Ndn. & Necdin \\
\hline 26.833 & Akap4 & A kinase (PRKA) anchor protein 4 \\
\hline 20.997 & Acrbp & Proacrosin binding protein \\
\hline 15.901 & ELOVL4 & $\begin{array}{l}\text { Elongation of very long chain fatty acids (FEN1/Elo2, } \\
\text { SUR4/Elo3, yeast)-like } 4\end{array}$ \\
\hline 12.168 & ODF4 & Outer dense fiber of sperm tails 4 \\
\hline 11.5361 & CCNA1 & Cyclin A1 \\
\hline 6.489 & Tdrd1 & Tudor domain containing 1 \\
\hline 5.510 & IL13RA2 & Interleukin 13 receptor, alpha 2 \\
\hline 4.728 & Adam2 & A disintegrin and metallopeptidase domain 2 \\
\hline 3.715 & CASC5 & Cancer susceptibility candidate 5 \\
\hline 3.008 & Cage1 & Cancer antigen 1 \\
\hline 2.69 & IGF2BP3 & Insulin-like growth factor 2 mRNA binding protein 3 \\
\hline 2.532 & GPATCH2 & G patch domain containing 2 \\
\hline 2.531 & IGSF11 & Immunoglobulin superfamily, member 11 \\
\hline 2.48 & JARID1B & Jumonji, AT rich interactive domain 1B (Rbp2 like) \\
\hline 2.167 & Prame & Preferentially expressed antigen in melanoma \\
\hline 1.937 & LYPD6B & LY6/PLAUR domain containing 6B \\
\hline 1.882 & Calr3 & Calreticulin 3 \\
\hline 1.573 & Tex14 & Testis expressed gene 14 \\
\hline 1.55 & Trap1a & Tumor rejection antigen P1A \\
\hline 1.46 & CTAGE5 & CTAGE family, member 5 \\
\hline 1.425 & Ctcf & CCCTC-binding factor \\
\hline 1.409 & Spa17 & Sperm autoantigenic protein 17 \\
\hline 1.303 & OIP5 & Opa interacting protein 5 \\
\hline 1.258 & Tsga10 & Testis specific 10 \\
\hline 1.229 & Cep55 & Centrosomal protein 55 \\
\hline 1.146 & PLAC1 & Placental specific protein 1 \\
\hline 1.087 & TTK & Ttk protein kinase \\
\hline 1.083 & Atad2 & ATPase family, AAA domain containing 2 \\
\hline 1.075 & SPAG1 & Sperm associated antigen 1 \\
\hline 1.06 & DPPA2 & Developmental pluripotency associated 2 \\
\hline 1.04 & NUF2 & NUF2, NDC80 kinetochore complex component \\
\hline
\end{tabular}

compared using gene array data (Table II). As shown, there was a downregulation in the expression of multiple CTA genes in prostate cancer cells in comparison to normal prostate.

\section{Effect of 5-AzaC on CTA Expression in RM-I Prostate Cancer Cells}

We evaluated the ability of 5-AzaC to induce increased expression of different CTA in prostate cancer cells. For this purpose, murine prostate cancer cells (RM-1 cells) were exposed to two different concentrations of 5-AzaC for 2 days. The expression of 13 different CTA and fold change was evaluated by quantitative PCR. Results are presented in Table III and Figure 5. 5-AzaC induced increased expression of nearly all CTA in RM-1 cells after 2 days of incubation. There appears to be a dose-related response, with greater expression seen at a concentration of $1 \mu \mathrm{M}$ of 5 -AzaC. At this concentration, difference was statistically significant $(P<0.001)$ for all 13 CTA tested.

To make sure that increased CTA gene expression translated to an increase in expression of the corresponding proteins we performed western blot for 2 randomly selected CTA out of 13 (Cep55 and Cyclin A1). As demonstrated in Figure 5B, expression of 
TABLE III. Change in the Expression of CTA in RM-I Cells After 5-Azacitidine Administration

\begin{tabular}{lcrr}
\hline & & \multicolumn{2}{c}{ Fold change expression (qRT-PCR) } \\
\cline { 3 - 3 } Gene description & RM-1 & RM-1 +5AzaC $0.5 \mu \mathrm{m}$ & RM-1+5AzaC $1.0 \mu \mathrm{m}$ \\
\hline Acrbp & 1.00 & 5.82 & 7.25 \\
Adam2 & 1.00 & 4.47 & 7.34 \\
Akap4 & 1.00 & 5.18 & 7.13 \\
Boris & 1.00 & 3.16 & 4.66 \\
Ccna1 & 1.00 & 4.29 & 8.28 \\
Cep55 & 1.00 & 6.21 & 10.75 \\
Dkk11 & 1.00 & 5.48 & 6.39 \\
Necdin & 1.00 & 3.36 & 3.89 \\
Odf4 & 1.00 & 5.52 & 9.74 \\
P1a & 1.00 & 3.23 & 6.21 \\
Spa17 & 1.00 & 1.76 & 2.86 \\
Tex15 & 1.00 & 0.76 & 2.07 \\
Tdrd1 & 1.00 & 2.77 & 3.63 \\
\hline
\end{tabular}

CEP55 and Cyclin A1 increased in a dose-dependent fashion with exposure to 5-AzaC.

We also exposed RM-1 prostate cancer cells to lenalidomide (at concentrations 0.5, 1.0, 2.0, and $10 \mu \mathrm{M})$, alone and in combination with 5-AzaC (at concentrations 0.5 and $1.0 \mu \mathrm{M}$ ). Exposure to lenalidomide did not alter expression of CTA by prostate cancer cells in either situation in comparison to controls, which were RM-1 cells for lenalidomide alone and RM-1 cells +5-AzaC for the combined group.

\section{DISCUSSION}

The difficulty in treating metastatic, especially hormone-resistant, prostate cancer has long troubled researchers and clinicians alike. Recent advances in the understanding of tumor immunology have provided new direction in the search for novel therapeutic strategies. Immunotherapy holds promise for the treatment of prostate cancer and other urologic malignancies and the use of antigen-presenting cells (APC) has shown some success in the treatment of prostate cancer. Dendritic cells, as the most effective APC, play a critical role in induction of innate and adaptive antitumor immune responses. Due to their role in generating immune response, DC emerged as attractive candidates for vaccination protocols in cancer therapy. Development of DC therapy has been and remains a multi-step process comprising cell generation, maturation, antigen loading and delivery, and failure to optimize any one of these steps could lead to an ineffective vaccine. Thus, for immunotherapeutic applications, it appears very important to identify factors that might affect the differentiation, maturation and function of DC [10].

In this paper, we examine the effect of epigenetic modification and immunomodulation on DC and prostate cancer cells in vitro. 5-AzaC and lenalidomide have been used in combination with other chemotherapeutic agents with variable results in the treatment of prostate cancer [11-16]. The addition of lenalidomide to 5-AzaC has been shown to be of therapeutic benefit in the treatment of certain hematologic malignancies [17-19]. Despite the disappointing results of the MAINSAIL trial which was stopped prematurely due to decreased overall survival with lenalidomide, docetaxel and prednisone compared to docetaxel and prednisone [20], there have nevertheless been multiple encouraging studies showing activity of lenalidomide in prostate cancer $[16,21-23]$. Our hypothesis was that combining the immunomodulatory effects of lenalidomide with the epigenetic modification of 5-AzaC in the treatment of prostate cancer might yield better results than the separate combination of these agents with chemotherapeutic agents [24], which in most cases act as immunosuppressants and might actually counteract the actions of immunostimulatory drugs.

In our experiments, 5 -AzaC resulted in a significant modulation of DC cytokine secretion, namely IL-12p70 and IL-15. We did not investigate the mechanisms of these changes. Epigenetic regulation of cytokine genes is a key factor in the initiation of immune response and, accordingly, 5-AzaC might influence DC gene expression. 5-AzaC as well as lenalidomide are compounds with anti-tumor activity. One of the mechanisms by which these drugs could enhance anti-cancer immunity may be through 

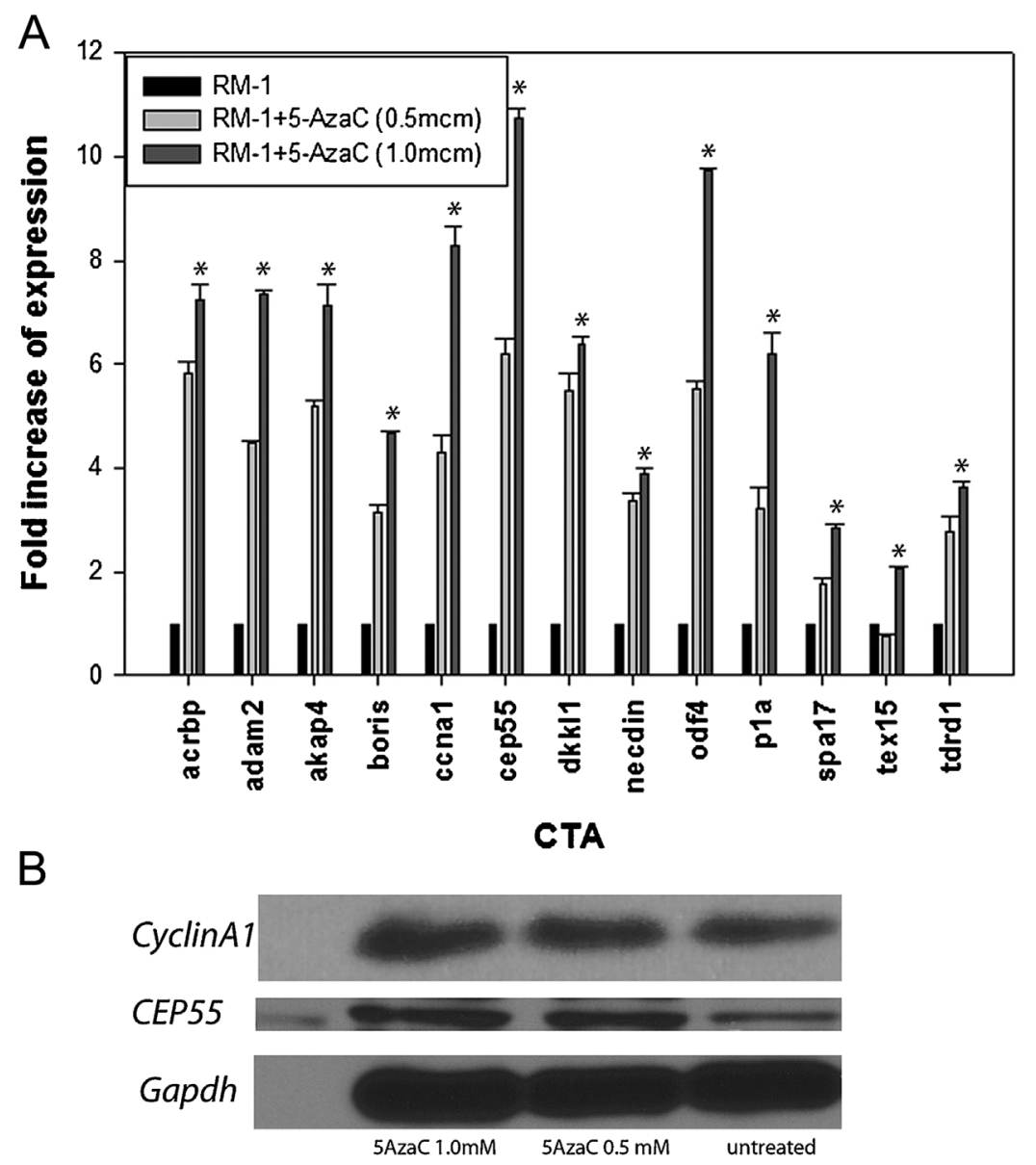

Fig. 5. RM-I cells were cultured in complete medium in a humidified atmosphere containing $5 \% \mathrm{CO}_{2}$ maintained at $37^{\circ} \mathrm{C}$. The day before treatment, cells were incubated in 6-well plates. After overnight incubation, RM-I cells were treated for $48 \mathrm{hr}$ with 5 -azaC at concentrations of 0.5 and $1.0 \mu \mathrm{M}$. Untreated cells provided the control. A: For qRT-PCR analysis, cells were harvested and cDNA prepared. The expression level of the 13 CTA genes were determined by PCR as indicated in the "Materials and Methods". Combined results from three independent experiments are shown. B: For western blot analyses, cells were harvested at the appropriate time, washed, and lysed with lysis buffer. The protein concentration in the resulting lysate was determined using a bicinchoninic acid protein assay kit (Pierce Biotechnology, Rockford, IL). Immunoblotting was conducted by standard protocols with an equal amount of total protein $(10 \mu \mathrm{g})$ per lane. Antibodies specific for Cyclin AI and CEP55 were used to detect protein expression. Protein expression of Cyclin AI and CEP55 was normalized to the expression of GAPDH. ${ }^{*}$ Depicts statistically significant difference in comparison to untreated RM-I cells.

enhanced dendritic cell function. One possible mode of action by which our study compounds may be immunomodulatory is by the induction of DC maturation by the upregulation of key molecules. We assessed the phenotypic markers of maturation and there were significant increases in CD86, CD80, CD40, CD205, MHC Class1, MHC Class II expression in DC exposed to the combination of 5-AzaC and lenalidomide (Fig. 2). There was also significant increase of the DC ability to stimulate T cells in the mixed leukocyte reaction with addition of 5-AzaC and lenalidomide to DC culture (Fig. 4). The effect was dose-dependent and statistically significant. These results suggest that the combination of 5-AzaC and lenalidomide might increase proinflammatory functions of DC, and thus should improve antitumor activity of DC-based vaccines.

We also examined the effect of 5-AzaC and lenalidomide on prostate cancer cells. First, we evaluated the expression of multiple CTA by RM- 1 cells. We have been successful in identifying 35 CTA that are downregulated in prostate tumor. This was achieved using an Affymetrix GeneChip Mouse Genome 4302.0 microarrays to assess differential gene expression in prostate tumor and normal samples. To confirm the relative fold change values obtained by microarray analyses, we performed qRT-PCR assays for all 35 genes. All genes tested showed similar expression patterns for both qRT-PCR and microarray assays. 
Epigenetic events, particularly DNA methylation, appear to be the primary mechanism regulating CTA expression. The first evidence that CTA expression was regulated by DNA methylation was provided by Weber et al. [3] Promoter methylation is the molecular mechanism directly responsible for the highly heterogeneous intratumor expression of CTA. We speculated that 5-AzaC would induce increased expression of downregulated CTA in prostate cancer tissue and should make cells more accessible to host immune system. In fact, no major up-regulation of CTA expression should be expected in tissues expressing constitutively high levels of CTA because of their heavily hypomethylated promoter, whereas a strong up-regulation should be anticipated in tissues expressing low baseline levels of CTA as the result of an extensively hypermethylated CTA promoter.

CTA include genes involved in cell cycle regulation, apoptosis, protein synthesis and degradation as well as transcription factors, and oncogenes [25]. Not surprisingly, CTA are oftentimes upregulated in cancer. For example, CAGE is frequently found to be hypomethylated in prostate cancer which results in high expression. Several studies have demonstrated aberrant expression of AKAP-4 in prostate cancer making it a potential biomarker candidate. However, CTA expression is not always upregulated in cancer cells. Necdin expression, for example, is repressed in several tumor cell types including melanoma, prostate and breast cancer cell lines. In our study, it was interesting to see downregulation of multiple CTA in our prostate cancer model.

The CTA found to be most downregulated in prostate cancer cells on gene microarray were used as markers for further investigation with quantitative PCR and Western blots. RM-1 cells were exposed to 5 -AzaC at concentrations of 0.5 and $1.0 \mu \mathrm{m}$ and qPCR was performed to compare the expression of various CTA before and after treatment. Results indicate that expression of nearly all CTA was increased by exposure of cells to 5-AzaC in a statistically significant dose-related response. To ensure that this finding would translate into actual protein expression, Western blots were used to confirm the trend of CTA upregulation with 5-AzaC exposure. CEP55, one of the genes investigated, is a known CTA found in breast, gastric, and bladder cancer [26-28] as well as in prostate cancer [29]. Western blot results for CEP55 and Cyclin 1A confirmed increased expression after exposure to 5-AzaC. Addition of lenalidomide alone or in combination with 5-AzaC does not seem to affect the expression of CTA by prostate cancer cells.

The current use of agents targeting epigenetic changes has become a topic of intense interest in cancer research. In this regard, 5-AzaC represents a promising epigenetic modulator [25], which has been studied in the prostate cancer environment. Our results suggest that $5-\mathrm{AzaC}$ might increase antitumor immune response through upregulation of CTA and effect on DC. Lenalidomide is an immunomodulatory compound with anti-inflammatory, immunomodulatory and anticancer activity [16]. Combination of these agents showed promise in modifying immune response which could prove relevant in design of immune vaccines. Our future goal is to test this hypothesis in a mouse model in vivo and to work toward delineating the exact mechanism for the synergistic effects seen in the combination of these compounds. If clinical benefit can be proven in solid organ malignancies, it is possible that this combination could be added to current adoptive immunotherapeutic techniques to achieve greater efficacy. Though in our work lenalidomide did not appear to have direct effects on prostate cancer cells, it did show immunomodulatory effects on DC and may contribute to antitumor response.

There is growing evidence suggesting that the combination of drugs with different mechanisms of action might offer a potential benefit especially when positive effects of compounds are synergistic while sparing potential side effects and toxicities. Combined therapy with 5-AzaC and lenalidomide appears to be a potentially promising option for immunotherapy for prostate cancer.

\section{REFERENCES}

1. Li LC, Carroll PR, Dahiya R. Epigenetic changes in prostate cancer: Implication for diagnosis and treatment. J Natl Cancer Inst 2005;97(2):103-115.

2. Krishnadas DK, Bai F, Lucas KG. Cancer testis antigens and immunotherapy. ImmunoTargets Ther 2013;2:11-19.

3. Weber J, Salgaller M, Samid D, Johnson B, Herlyn M, Lassam N, Treisman J, Rosenberg SA. Expression of the MAGE-1 tumor antigen is up-regulated by the demethylating agent 5-aza- $2^{\prime}$ deoxycytidine. Cancer Res 1994;54(7):1766-1771.

4. Guo ZS, Hong JA, Irvine KR, Chen GA, Spiess PJ, Liu Y, Zeng G, Wunderlich JR, Nguyen DM, Restifo NP, Schrump DS. De novo induction of a cancer/testis antigen by 5-aza-2'-deoxycytidine augments adoptive immunotherapy in a murine tumor model. Cancer Res 2006;66(2):1105-1113.

5. Dubovsky JA, McNeel DG. Inducible expression of a prostate cancer-testis antigen, SSX-2, following treatment with a DNA methylation inhibitor. Prostate 2007;67(16):1781-1790.

6. Lim SH, Zhang Y, Zhang J. Cancer-testis antigens: The current status on antigen regulation and potential clinical use. Am J Blood Res 2012;2(1):29-35.

7. Kotla V, Goel S, Nischal S, Heuck C, Vivek K, Das B, Verma A. Mechanism of action of lenalidomide in hematological malignancies. J Hematol Oncol 2009;2:36.

8. Acebes-Huerta A, Huergo-Zapico L, Gonzalez-Rodriguez AP, Fernandez-Guizan A, Payer AR, Lopez-Soto A, Gonzalez S. 
Lenalidomide induces immunomodulation in chronic lymphocytic leukemia and enhances antitumor immune responses mediated by NK and CD4 $\mathrm{T}$ cells. Biomed Res Int 2014;2014:265840.

9. Chong EA, Ahmadi T, Aqui NA, Svoboda J, Nasta SD, Mato AR, Walsh KM, Schuster SJ. Combination of lenalidomide and rituximab overcomes rituximab resistance in patients with indolent B-cell and mantle cell lymphomas. Clin Cancer Res 2015;21(8):1835-1842.

10. Jahnisch H, Fussel S, Kiessling A, Wehner R, Zastrow S, Bachmann M, Rieber EP, Wirth MP, Schmitz M. Dendritic cellbased immunotherapy for prostate cancer. Clin Dev Immunol 2010;2010:517493.

11. Thibault A, Figg WD, Bergan RC, Lush RM, Myers CE, Tompkins A, Reed E, Samid D. A phase II study of 5-aza-2'deoxycytidine (decitabine) in hormone independent metastatic (D2) prostate cancer. Tumori 1998;84(1):87-89.

12. Shang D, Liu Y, Liu Q, Zhang F, Feng L, Lv W, Tian Y. Synergy of 5-aza-2'-deoxycytidine (DAC) and paclitaxel in both androgen-dependent and -independent prostate cancer cell lines. Cancer Lett 2009;278(1):82-87.

13. Galsky MD, Vogelzang NJ. Docetaxel-based combination therapy for castration-resistant prostate cancer. Ann Oncol 2010;21(11):2135-2144.

14. Mathew P, Tannir N, Tu SM, Carter CM, Bekele NB, Pagliaro L. A modular Phase I study of lenalidomide and paclitaxel in metastatic castration-resistant prostate cancer following prior taxane therapy. Cancer Chemother Pharmacol 2010;65(4):811-815.

15. Nabhan C, Petrylak DP. The role of IMiDs alone or in combination in prostate cancer. Clin Genitourin Cancer 2012;10(3):141-146

16. Henry JY, Lu L, Adams M, Meyer B, Bartlett JB, Dalgleish AG, Galustian C. Lenalidomide enhances the anti-prostate cancer activity of docetaxel in vitro and in vivo. Prostate 2012;72(8):856-867.

17. Sekeres MA, List AF, Cuthbertson D, Paquette R, Ganetzky R, Latham D, Paulic K, Afable M, Saba HI, Loughran TP, Jr., Maciejewski JP. Phase I combination trial of lenalidomide and azacitidine in patients with higher-risk myelodysplastic syndromes. J Clin Oncol 2010;28(13):2253-2258.

18. Pollyea DA, Kohrt HE, Gallegos L, Figueroa ME, Abdel-Wahab O, Zhang B, Bhattacharya S, Zehnder J, Liedtke M, Gotlib JR, Coutre S, Berube C, Melnick A, Levine R, Mitchell BS, Medeiros BC. Safety, efficacy and biological predictors of response to sequential azacitidine and lenalidomide for elderly patients with acute myeloid leukemia. Leukemia 2012;26(5):893-901.

19. Ramsingh G, Westervelt P, Cashen AF, Uy GL, StockerlGoldstein K, Abboud CN, Bernabe N, Monahan R, Dipersio JF, Vij R. A phase 1 study of concomitant high-dose lenalidomide and 5-azacitidine induction in the treatment of AML. Leukemia 2013;27(3):725-728.
20. Petrylak DP, Vogelzang NJ, Budnik N, Wiechno PJ, Sternberg CN, Doner K, Bellmunt J, Burke JM, de Olza MO, Choudhury A, Gschwend JE, Kopyltsov E, Flechon A, Van As N, Houede N, Barton D, Fandi A, Jungnelius U, Li S, de Wit R, Fizazi K. Docetaxel and prednisone with or without lenalidomide in chemotherapy-naive patients with metastatic castration-resistant prostate cancer (MAINSAIL): A randomised, double-blind, placebo-controlled phase 3 trial. Lancet Oncol 2015;16(4):417-425.

21. Zabransky DJ, Smith HA, Thoburn CJ, Zahurak M, Keizman D, Carducci M, Eisenberger MA, McNeel DG, Drake CG, Antonarakis ES. Lenalidomide modulates IL-8 and antiprostate antibody levels in men with biochemically recurrent prostate cancer. Prostate 2012;72(5):487-498.

22. Nabhan C, Patel A, Villines D, Tolzien K, Kelby SK, Lestingi TM. Lenalidomide monotherapy in chemotherapy-naive, castration-resistant prostate cancer patients: Final results of a phase II study. Clin Genitourin Cancer 2014;12(1):27-32.

23. Wang J, McGuire TR, Britton HC, Schwarz JK, Loberiza FR, Jr., Meza JL, Talmadge JE. Lenalidomide and cyclophosphamide immunoregulation in patients with metastatic, castration-resistant prostate cancer. Clin Exp Metastasis 2015;32(2):111-124.

24. Singal R, Ramachandran K, Gordian E, Quintero C, Zhao W, Reis IM. Phase I/II study of azacitidine, docetaxel, and prednisone in patients with metastatic castration-resistant prostate cancer previously treated with docetaxel-based therapy. Clin Genitourin Cancer 2015;13(1):22-31.

25. Fratta E, Coral S, Covre A, Parisi G, Colizzi F, Danielli R, Nicolay HJ, Sigalotti L, Maio M. The biology of cancer testis antigens: Putative function, regulation and therapeutic potential. Mol Oncol 2011;5(2):164-182.

26. Inoda S, Morita R, Hirohashi $Y$, Torigoe $T$, Asanuma $H$, Nakazawa E, Nakatsugawa M, Tamura $Y$, Kamiguchi $K$, Tsuruma T, Terui T, Ishitani K, Hashino S, Wang Q, Greene MI, Hasegawa T, Hirata K, Asaka M, Sato N. The feasibility of Cep55/c10orf3 derived peptide vaccine therapy for colorectal carcinoma. Exp Mol Pathol 2011;90(1):55-60.

27. Colak D, Nofal A, Albakheet A, Nirmal M, Jeprel H, Eldali A, Al-Tweigeri T, Tulbah A, Ajarim D, Malik OA, Inan MS, Kaya $\mathrm{N}$, Park BH, Bin Amer SM. Age-specific gene expression signatures for breast tumors and cross-species conserved potential cancer progression markers in young women. PLoS ONE 2013;8(5):e63204.

28. Singh PK, Srivastava AK, Rath SK, Dalela D, Goel MM, Bhatt ML. Expression and clinical significance of Centrosomal protein 55 (CEP55) in human urinary bladder transitional cell carcinoma. Immunobiology 2015;220(1):103-108.

29. Shiraishi T, Terada N, Zeng $\mathrm{Y}$, Suyama T, Luo J, Trock B, Kulkarni P, Getzenberg RH. Cancer/Testis Antigens as potential predictors of biochemical recurrence of prostate cancer following radical prostatectomy. J Transl Med 2011;9:153. 